\title{
STUCK
}

\section{KAREN LANGE}

California Polytechnic State University, San Luis Obispo

Composed as an ethereal, tenuous experience, STUCK was designed to embrace light and darkness. A collaborative design project STUCK was an installation designed, funded, created, fabricated, and constructed by 18 students in a thesis studio. The installation served as showcase to present each of the student's thesis research books. STUCK was conceptually developed over a month through sketches and full scale prototyping with construction and exhibition occurring over a five day period. The tight time line required the participation of all 18 students - peeling, sticking, and adhering 35 miles of packaging tape across a steel uni-strut structure to form two main atria. Additional occupiable tendrils stretched to attach to the main structure, stabilizing and forming tunnels and slings into which to climb and recline. Visitors were able to gather and browse thesis books in the atria before climbing into the tendrils for intimate reading. As darkness reduced the light, STUCK transformed from reading space to alternate experience; reading became impossible and skin became digital scrim, transformed by music tempo and volume, and array of videos projected onto the skin. In this incarnation, the focus shifted from form and books to exploitation and manipulation of space, perception, and material properties.

STUCK was a collaborative gallery installation produced by the students of Studio 400_2015, an architectural thesis studio at California Polytechnic State University, San Luis Obispo. STUCK supported a variety of interactive experiences, opening and exploring the relationships between book, user, material, space, and collective group.

The use of a collaborative learning experience within thesis serves to unite the students through shared involvement, assisting them in their efforts to become a cohesive entity, a functioning and functional studio. This entity, as also formed through field trips, all nighters, exhibitions, and critiques, allows the students to trust their studio peers becoming a think tank (or "do tank," per conference plenary speaker, Alejandro Aravena) in order to be comfortable in the studio but also in thinking creatively individually. Common experience which is rewarded through action, response, and publication, reinforces the strength of the group, but in addition, the individual gains power through association.

STUCK was a part of a long term academic agenda, Bookshow, that makes up part of the Studio 400 curriculum. Across years Bookshow has formed a collaborative, creative bond and competition beyond the constraints of the existing academic year. Studio 400 (named after the studio room number, joining past and future students across time) is not only a location but a state of mind. Its very nature is one of competition between years, not within the year. Studio as a productive whole works when the participants know, like, and trust one another. STUCK, as well as all past Bookshow installations, is a generator of confidence and imagination, speaking to the collegiality of the group, the common goal of display, shared experience of design and construction, but also about its shared experiential nature. Bookshow installations are a way for students to share and disseminate their research; the individual books while interesting become compelling in an environment made specific to their consumption. 

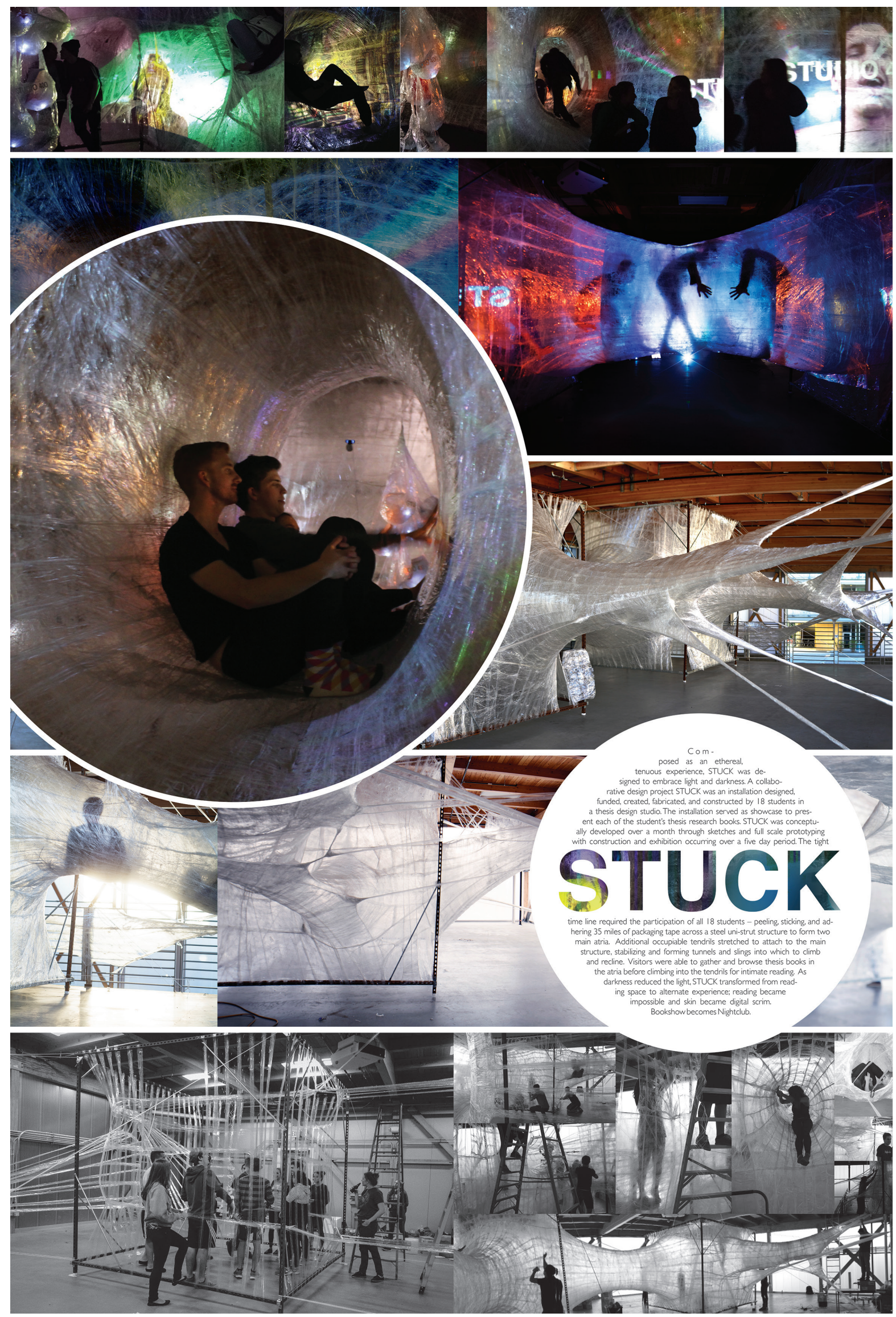